\title{
Soluble Fms-Like Tyrosin Kinase-1 and Placental Growth Factor Biomarkers Integrated for Predictability of Preeclampsia
}

\author{
Mahmoud Abosrea*, Ahmed Mousad* and Asmaa Elfallah ** \\ *Department of Obstetrics \& Gynaecology, Faculty of Medicine, Benha University, Benha. Egypt. \\ **Department of clinical pathology, Faculty of Medicine, Benha University, Benha. Egypt.
}

Submission: September 10, 2019, Published: September 18, 2019

*Corresponding author: Mahmoud Abosrea, Department of Obstetrics \& Gynecology, Benha University, Egypt

\begin{abstract}
Background: Biomarkers in diagnostic and prognostic approaches in obstetric research efforts are gaining a global interest however the sensitivity and specificity of those biomarkers are considered an issue of research debate

Aim: To investigate usefulness and reliability of implementing the usage of sFlt-1/PIGF ratio for predictability of the presence or absence of preeclampsia development.

Methodology: A cohort and randomized research study was conducted on 50 pregnant cases, the course of pregnancy was observed extensively in randomly selected pregnant women. Personal and history data, personal habits, the course and pregnancy clinical outcome was recorded. Research study subjects were equally categorized in two groups as follows: the control group and the preeclampsia group. Serum levels of sFlt-1 and PIGF in obtained samples was determined retrospectively by usage of Elecsys assays on an electrochemiluminescence immunoassay platform and implemented to calculate the sFlt-1/PIGF ratio.

Result: Comparative statistical analysis of soluble fms-like tyrosine kinase 1, placental growth factor and sFLT/PIGF ratio among term and preterm preeclampsia cases showed highly statistical significant difference between term and preterm research categories of preeclampsia cases as regards soluble fms-like tyrosine kinase 1 (pg/ml) 24-28 GA, 28-31 GA (p values <0.001), besides there was statistical significant difference as regards PlGF (pg/ml) 24-28 GA, PlGF (pg/ml) 28-32 GA ( $\mathrm{p}$ values $=0.021,0.011$ consecutively).
\end{abstract}

Conclusion: Angiogenic factors are cornerstone biomarkers that could be applied as a predictability tool for preeclampsia particularly when integrated in the form of ratio.

\section{Introduction}

Preeclampsia is a multisystem disease and is one of the frequently presented clinical scenarios in every day obstetric practice. Researchers all over the globe are frequently trying to innovatively advance the diagnostic and therapeutic protocols to enhance the level of management of this obstetric issue [1,2]. Preeclampsia as a heterogeneous disorder it impacts in a negative manner the physiological balances at both maternal and fetal levels that causes in some cases a serious threat on maternal and neonatal lives and is a highly complex disease in its pathophysiological nature with various risk factors that interplay in its development $[3,4]$. Biomarkers in diagnostic and prognostic approaches in obstetric research efforts are gaining a global interest however the sensitivity and specificity of those biomarkers are considered an issue of research debate. pathological and clinical courses of preeclampsia are highly variable and are con sidered highly challenging in some situations as mild forms of the disease could be suddenly progressive within a short period of time causing prematurity and morbid maternal issues such as post-partum hemorrhage $[5,6]$.

Correlated hematological affection are considered one of the lethal sequalae of preeclampsia if not properly managed such as HELLP syndrome, end organ damage particularly in cases with severe proteinuria and CNS symptoms denoting rapid progression of the disease $[7,8]$. Preeclampsia could develop denovo or on top of hypertensive disorders preexisting before conception and could develop on top of gestational hypertension, maternal, fetal and placental factors interplay in the complex pathological development of the disease which raised the interest to investigate the possible biomarkers that could be assayed aiding in detectability of abnormal changes in serum levels. Abnormal 
placental vascular remodeling and changes could be the cornerstone issue that if investigated could elucidate the pathophysiological roots of the disease development since placental hypo-perfusion is one of the real challenges to the obstetrician in disease management and decision making $[9,10]$.

Endothelial dysfunction is revealed and displayed by various research groups to be the cornerstone issue in triggering the disease development course such as placental growth factor (PIGF) and soluble fms-like tyrosine kinase-1 (sFlt-1) circulating angiogenic factors. Angiogenic factors secreted by the placenta are the cornerstone regulators of placental vascular system performance $[11,12]$. High fms-like tyrosine kinase-1 serum levels (anti-angiogenic protein) and low placental growth factor serum levels (pro-angiogenic protein), are highly reliable biomarkers for consecutive pathological development of preeclampsia. However, the exact cutoff values are an issue of research debate and the current clinical profile and routine investigative tools are highly variable and require support by more early investigative tools for early prediction of disease development $[13,14]$.

\section{Aim of the Work}

To investigate usefulness and reliability of implementing the usage of sFlt-1/PIGF ratio for predictability of the presence or absence of preeclampsia development.

\section{Methodology}

This cohort and randomized research study were performed on a total of 50 pregnant cases recruited from the Department of Gynecology and Obstetrics in Benha University Hospital during a period from May 2018 to April 2019. We had ethical approval for this study protocol from Benha Faculty of Medicine ethical committee; also, all included participants signed full informed written consents. The course of pregnancy was observed extensively in randomly selected pregnant women. Personal and history data, personal habits, the course and pregnancy clinical outcome was recorded. Cases were presented with and signed an informed written consent. Research study subjects were equally categorized in two research groups as follows the control research group and the preeclampsia research group.

The control research group involved cases that are normotensive and no proteinuria all the way through gestation. The diagnostic clinical features for preeclampsia research group have been clinically defined as hypertension(systolic blood pressure $\geq 140 \mathrm{~mm} \mathrm{Hg}$ and diastolic blood pressure $\geq 90 \mathrm{~mm} \mathrm{Hg}$ after 20 th gestational weeks) and proteinuria (diagnosed by observation of $300 \mathrm{mg}$ of protein excreted in 24-hour urine collected .Maternal blood sample was obtained at two times at $24+1$ to $28+0$ th ges- tational weeks and at $28+1$ to $32+0$ gestational weeks.

\section{Sampling}

5 milliliters of venous blood were withdrawn from each subject and collected in serum separating tubes. Clotted samples were centrifuged within one hour of sampling, at 3000rpm for 10 minutes. The serum was then separated and kept in eppendorf tubes and stored at $-20^{\circ} \mathrm{C}$ till time of assay. Serum levels of sFlt- 1 and PIGF in obtained samples were determined retrospectively by usage of Elecsys assays on an electrochemiluminescence immunoassay platform (Cobase analyzer, Roche Diagnostic, Germany) and implemented to calculate the sFlt-1/PIGF ratio.

\section{Statistical Analysis}

Data were collected, revised, coded and entered to the Statistical Package for Social Science (IBM SPSS) version 23. Data were checked for normality using Kolmogorov-Smirnov test and the quantitative data with parametric distribution were presented as mean, standard deviations and ranges and compared using independent t-test between two groups and One Way ANOVA between more than two groups while with non parametric distribution were presented as median with inter-quartile range (IQR) and compared using Mann-Whitney test between two groups. Also, the comparison regarding qualitative variables was done by using Chi-square test and/or Fisher exact test when the expected count was found less than 5 in any cell. The confidence interval was set to $95 \%$ and the margin of error accepted was set to $5 \%$. So, the p-value was considered significant at the level of $<0.05$.

\section{Result}

The demographic and clinical features of the research study groups recruited was displayed in Table 1 in which there was no statistical significant difference as regards age, BMI, nullipara, Gestational age (weeks), 2nd trimester, Gestational age (weeks), 3rd trimester, current smokers, chronic disease, drugs, family history of PE, PE in previous pregnancies, GDM in previous pregnancies $(\mathrm{p}$ values $=0.440,0.172,0.774,0.875,0.783,0.712$, $0.384,0.349,0.508,0.122,0.551$ consecutively) Among the cohort of 50 patients 25 patients developed clinical preeclampsia: 15 before 37 gestational weeks and 10 after 37 gestational weeks As regard the features of the research study cohort at time of delivery there was a highly statistical significant difference between control research group and preeclampsia developing after and before 37 gestational weeks as regards IUGR development, APGAR score, birth weight, gestational age weeks, mode of delivery ( $\mathrm{p}$ values $=0.001,<0.001,<0.001,<0.001,<0.001$ consecutively) Table 2.

Table 1: Demographic and clinical characteristics of the research groups (control and PE).

\begin{tabular}{|c|c|c|c|c|}
\hline & Control Group No. $=\mathbf{2 5}$ & PE Group No. $=\mathbf{2 5}$ & Test Value & P-value \\
\hline Age (years) & $29.35 \pm 4.3$ & $30.4 \pm 5.2$ & $0.778 \bullet$ & 0.44 \\
\hline BMI (kg/m2) & $26.3 \pm 4.2$ & $28.4 \pm 6.3$ & $1.387 \bullet$ & 0.172 \\
\hline Nullipara & $10(40.0 \%)$ & $11(44.0 \%)$ & $0.082^{*}$ & NS \\
\hline
\end{tabular}




\section{Journal of Gynecology and Women's Health}

\begin{tabular}{|c|c|c|c|c|c|}
\hline $\begin{array}{l}\text { Gestational age (weeks), } \\
\text { 2nd trimester }\end{array}$ & $26.3 \pm 4.1$ & $26.5 \pm 4.8$ & $0.158 \bullet$ & 0.875 & NS \\
\hline $\begin{array}{c}\text { Gestational age (weeks), } \\
\text { 3rd trimester }\end{array}$ & $31.2 \pm 3.4$ & $30.9 \pm 4.2$ & $0.278 \bullet$ & 0.783 & NS \\
\hline Current smokers & $5(20.0 \%)$ & $4(16.0 \%)$ & $0.136^{*}$ & 0.712 & NS \\
\hline Chronic disease & $4(16.0 \%)$ & $2(8.0 \%)$ & $0.758^{*}$ & 0.384 & NS \\
\hline Drugs & & & $2.100^{*}$ & 0.349 & NS \\
\hline Methyldopa & $2(8.0 \%)$ & $3(12.0 \%)$ & & & \\
\hline Others & $4(16.0 \%)$ & $1(4.0 \%)$ & & & \\
\hline No & $19(76.0 \%)$ & $21(84.0 \%)$ & & & \\
\hline Family history of PE & $5(20.0 \%)$ & $7(28.0 \%)$ & $0.439 *$ & 0.508 & NS \\
\hline $\begin{array}{l}\text { PE in previous pregnan- } \\
\text { cies }\end{array}$ & $5(20.0 \%)$ & $10(40.0 \%)$ & $2.381^{*}$ & 0.122 & NS \\
\hline $\begin{array}{l}\text { GDM in previous preg- } \\
\text { nancies }\end{array}$ & $1(4.0 \%)$ & $2(8.0 \%)$ & $0.355^{*}$ & 0.551 & NS \\
\hline
\end{tabular}

*: Data were presented as numbers and percentages and compared using Chi-square test

$\because$ Data were presented as mean $\pm \mathrm{SD}$ and compared using independent $\mathrm{t}$-test

Table 2: Features of the research study cohort at time of delivery.

\begin{tabular}{|c|c|c|c|c|c|c|}
\hline & Control Group No. = 25 & PE $>$ 37 GA No. $=\mathbf{1 5}$ & PE $<\mathbf{3 7 ~ G A ~ N o . ~ = ~ 1 0 ~}$ & Test Value & P-value & Sig. \\
\hline IUGR & $0(0.0 \%)$ & $3(20.0 \%)$ & $5(50.0 \%)$ & $13.542 *$ & 0.001 & HS \\
\hline Apgar score & $10(8-10)$ & $9(7-10)$ & $7(5-8)$ & $3.812 \neq$ & $<0.001$ & HS \\
\hline Birth weight & $3512 \pm 215$ & $3125 \pm 250$ & $2730 \pm 218$ & $45.292 \bullet$ & $<0.001$ & HS \\
\hline Gestational age (weeks) & $39.3 \pm 1.3$ & $38.6 \pm 0.9$ & $32.1 \pm 2.1$ & $99.969 \bullet$ & $<0.001$ & HS \\
\hline Mode of delivery & & & & $33.333^{*}$ & $<0.001$ & HS \\
\hline NVD & $20(80.0 \%)$ & $0(0.0 \%)$ & $0(0.0 \%)$ & & & \\
\hline CS & $5(20.0 \%)$ & $15(100.0 \%)$ & $10(100.0 \%)$ & & \\
\hline
\end{tabular}

*: Data were presented as numbers and percentages and compared using Chi-square test

$\because$ Data were presented as mean \pm SD and compared using One Way ANOVA

\#: Data were presented as median with interquartile range (IQR) and compared using Kruskall-Wallis test.

Table 3: Maternal serum levels of soluble fms-like tyrosine kinase 1 (sFLT), placental growth factor (PIGF) and sFLT/ PIGF ratio in cases with preeclampsia and matched research controls.

\begin{tabular}{|c|c|c|c|c|c|}
\hline & Control Group & PE Group & Test Value $\neq$ & P-value & Sig. \\
\hline sFLT (pg/ml) 24-28 GA & $1409(415.35-2541)$ & $2130(560.3-4863)$ & 5.612 & $<0.001$ & HS \\
\hline sFLT(pg/ml) 28-31 GA & $1519(495-2842)$ & $3137(498.5-6513)$ & 9.124 & $<0.001$ & HS \\
\hline PIGF (pg/ml) 24-28 GA & $521(210-2031)$ & $198(35.4-418.3)$ & 4.812 & $<0.001$ & HS \\
\hline PIGF (pg/ml) 28-32 GA & $585.3(240-2320)$ & $147.5(23.8-385)$ & 8.614 & $<0.001$ & HS \\
\hline sFLT/PLGF 24-28 & $2.41(1.3-6.45)$ & $8.86(1.95-98.6)$ & 7.315 & $<0.001$ & HS \\
\hline sFLT/PLGF 28-31 & $2.125(0.713-9.73)$ & $15.35(0.612-117.3)$ & 8.647 & $<0.001$ & HS \\
\hline
\end{tabular}

\#: Data were presented as median with interquartile range (IQR) and compared using Mann-Whitney test

Table 4: Comparative statistical analysis of soluble fms-like tyrosine kinase 1 (sFLT), placental growth factor (PIGF) and sFLT/PIGF ratio among term and preterm preeclampsia cases.

\begin{tabular}{|c|c|c|c|c|c|}
\hline & PE $>$ 37 GA No. = 15 & PE < 37 GA No. = 10 & Test value & P-value & Sig. \\
\hline sFLT (pg/ml) 24-28 GA & $827.6(352.8-2670)$ & $2870(780-4863)$ & 6.254 & $<0.001$ & HS \\
\hline sFLT(pg/ml) 28-31 GA & $925.4(385.6-2412)$ & $4203(1098.6-6513)$ & 9.314 & $<0.001$ & HS \\
\hline PIGF (pg/ml) 24-28 GA & $215(135.6-418.3)$ & $67.9(35.4-198.4)$ & 3.879 & 0.021 & S \\
\hline PIGF (pg/ml) 28-32 GA & $187.6(121.8-385)$ & $56.9(23.8-137.2)$ & 4.219 & 0.011 & S \\
\hline sFLT/PLGF 24-28 & $2.315(1.95-10.971)$ & $35.7(27.25-98.6)$ & 9.138 & $<0.001$ & HS \\
\hline sFLT/PLGF 28-31 & $4.314(0.612-3.12)$ & $86.4(37.6-117.3)$ & 7.145 & $<0.001$ & HS \\
\hline
\end{tabular}

\#: Data were presented as median with interquartile range (IQR) and compared using Mann-Whitney test 
Statistical comparative analysis of maternal serum levels of soluble fms-like tyrosine kinase 1 (sFLT), placental growth factor (PIGF) and SFLT/ PIGF ratio in cases with preeclampsia and matched research controls showed that there was a highly statistical significant difference as regards sFLT (pg/ml) 24-28 GA, sFLT(pg/ml) 28-31 GA, PlGF (pg/ml) 24-28 GA, PlGF (pg/ml) 28-32 GA, sFLT/PLGF 24-28 gestational age, sFLT/PLGF 28-31 gestational age ( $\mathrm{p}$ values $<0.001$ ) Table 3 . The Comparative statistical analysis of soluble fms-like tyrosine kinase 1, placental growth factor and sFLT/PIGF ratio among term and preterm preeclampsia cases revealed a highly statistical significant difference between term and preterm research categories of preeclampsia cases as regards soluble fms-like tyrosine kinase $1(\mathrm{pg} / \mathrm{ml}) 24$ 28 GA, 28-31 GA (p values <0.001), besides there was statistical significant difference as regards PIGF (pg/ml) 24-28 GA, PIGF $(\mathrm{pg} / \mathrm{ml})$ 28-32 GA (p values $=0.021,0.011$ consecutively) Table 4 .

\section{Discussion}

Preeclampsia is a common clinical scenario in obstetric every day practice and is well known as the disease of theories prior research groups of investigators support the theory that preeclampsia pathophysiological development course results from serum levels disproportion of placental angiogenic and antiangiogenic factors that negatively influence maternal vascular endothelial surface functional performance at molecular ,cellular and physiologic levels, causing the maternal and fetal characteristics observed in those clinical scenarios, previous studies similar to the current research study in approach and methodology showed that serum levels of sFlt-1 have been statistically significantly higher and PIGF significantly lower in cases that pathologically developed preeclampsia in comparison to cases that had a normal gestational clinical outcome [15].

The aim of using the sFlt-1 and PlGF biomarkers is to identify high-risk pregnant women who require intensive monitoring, and to rule out PE onset so avoiding unnecessary hospitalization. Furthermore, prior investigators have shown among their research studies that the ratio of sFlt-1to PIGF have been statistically significantly higher in cases that pathologically developed preeclampsia in comparison to cases that had a normal gestational outcome $[1,6,10]$. In an interesting manner prior research studies and research groups have revealed and displayed among their findings that, serum level of sFLT- 1 and the sFLT/PIGF ratio was statistically significantly higher among preterm deliveries in cases of preeclampsia in comparison to full term deliveries of cases having PE in b second and third gestational trimesters performed assays, and the PIGF serum level was statistically significantly lower among cases with preeclampsia and premature deliveries. Those research findings show great harmony and similarity top the current study findings and could be justified by the fact that angiogenic factors have a cornerstone role in cases having a pathologically developing preeclampsia process and that the more the imbalance in angiogenic factors secreted by the placenta the more advanced is the clinical presentation of the disease $[2,4,9]$.

On the other hand a prior research metanalysis have shown that the precision of PIGF, and sFLT1 assays in predictability of preeclampsia is very weak as regards sensitivity and specificity aspects making it of low value in clinical every day practice on the other hand various prior research studies have shown that the sFlt-1/PIGF ratio enhances and augments the statistical sensitivity as regards the predictability of preeclampsia clinical $[5,12,14]$.

\section{Conclusions and Recommendations for Future Research}

Angiogenic factors are cornerstone biomarkers that could be applied as a predictability tool for preeclampsia particularly when integrated in the form of ratio, however future research efforts should be multicentric in manner and should consider other variables such as racial and ethnic differences that could affect the serum levels of angiogenic markers secreted by the placenta.

\section{Conflict of Interest}

The author declared that they have no conflict of interest regards this article.

\section{References}

1. Hutcheon JA, Lisonkova S, Joseph KS (2011) Epidemiologyof preeclampsia and the other hypertensivedisorders of pregnancy. Best Pract Res Clin Obstet Gynaecol 25(4): 391-403.

2. Roberts JM, August PA, Bakris G, Barton JR, BernsteinIM, et al. (2013) Hypertension in pregnancy. Report of the American College of Obstetricians and Gynecologists' Task Force on Hypertension in Pregnancy. Obstet Gynecol 122(5): 1122-1131.

3. Phipps E, Prasanna D, Brima W, Jim B (2016) Preeclampsia: updates in pathogenesis, definitions, and guidelines. Clin J Am Soc Nephrol 11(6): 1102-1113.

4. Magee LA, von Dadelszen P (2018) State-of-the-art diagnosis and treatment of hypertension in pregnancy. Mayo Clin Proc 93(11): 16641677.

5. Karumanchi SA, Kee-Hak L, August P (2018) Preeclampsia: pathogenesis.

6. Stepan H, Schaarschmidt W, Jank A, Verlohren S, Kratzsch J, et al. (2010) Use of angiogenic factors (sFlt-1/PlGF ratio) to confirm the diagnosis of preeclampsia in clinical routine: first experience. Z Geburtshilfe Neonatol 214(6): 234-238.

7. Stepan H, Herraiz I, Schlembach D, Verlohren S, Brennecke S, et al. (2015) Implementation of the sFlt-1/PlGF ratio for prediction and diagnosis of pre-eclampsia in singleton pregnancy: implications for clinical practice. Ultrasound Obstet Gynecol 45(3): 241-246.

8. Herraiz I, Simon E, Gomez-Arriaga PI, Martinez-Moratalla JM, GarciaBurguillo A, et al. (2015) Angiogenesis-related biomarkers(sFlt-1/ PLGF) in the prediction and diagnosis of placental dysfunction: an approach for clinical integration. Int J Mol Sci 16(8): 19009-190026.

9. Herraiz I, Llurba E, Verlohren S, Galindo A (2018) Update on the diagnosis and prognosis of preeclampsia with the aid of the sFlt-1/ PlGF Ratio in singleton pregnancies. Fetal Diagn Ther 43(2): 81-89.

10. Uzan J, Carbonnel M, Piconne O, Asmar R, Ayoubi JM, et al. (2011) Preeclampsia: pathophysiology, diagnosis, and management. Vasc Health Risk Manag 7: 467-474. 
11. Kleinrouweler CE, Wiegerinck MM, Ris-Stalpers C, Bossuyt PM, Post VDJA, et al. (2012) Accuracy of circulating placental growth factor, vascular endothelial growth factor, soluble fms-like tyrosine kinase 1 and soluble endoglin in the prediction of pre-eclampsia: a systematic review and meta-analysis. BJOG 119(7): 778-787.

12. Chappell LC, Duckworth S, Seed PT, Griffin M, Myers J, et al. (2013) Diagnostic accuracy of placental growth factor in women with suspected preeclampsia: a prospective multicenter study. Circulation 128(19): 2121-2131.

13. Tan MY, Wright D, Koutoulas L, Akolekar R, Nicolaides KH, et al. (2017) Comparison of screening for pre-eclampsiaat 31-34 weeks' gestation by sFlt-1/PlGF ratio and a method combining maternal factors withsFlt-1 and PlGF. Ultrasound Obstet Gynecol 49(2): 201-208.

14. Lai J, Garcia-Tizon LS, Peeva G, Poon LC, Wright D, et al. (2014) Competing risks model in screening for preeclampsia by serum placental growth factor and soluble fms-like tyrosine kinase-1at 30-33 weeks' gestation. Fetal Diagn Ther 35(4): 240-248.

15. Klein E, Schlembach D, Ramoni A, Langer E, Bahlmann F, et al. (2016) Influence of the sFlt-1/PlGF ratioon clinical decision-making in women with suspected preeclampsia. PLoS One 11(5): e0156013.

\section{Your next submission with Juniper Publishers will reach you the below assets}

- Quality Editorial service

- Swift Peer Review

- Reprints availability

- E-prints Service

- Manuscript Podcast for convenient understanding

- Global attainment for your research

- Manuscript accessibility in different formats ( Pdf, E-pub, Full Tsext, Audio)

- Unceasing customer service

Track the below URL for one-step submission https://juniperpublishers.com/online-submission.php 